\title{
Article
}

\section{Microcrack Detection Using Spectral Response Data Alone}

\author{
Gee-Soo Lee ${ }^{1}$ (D) and Chan-Jung Kim ${ }^{2, *(D)}$ \\ 1 Department of Automotive Engineering, Tongmyong University, Busan 48520, Korea; gslee@tu.ac.kr \\ 2 Department of Mechanical Design Engineering, Pukyong National University, Busan 48513, Korea \\ * Correspondence: cjkim@pknu.ac.kr; Tel.: +82-51-629-6169
}

check for

updates

Citation: Lee, G.-S.; Kim, C.-J. Microcrack Detection Using Spectral Response Data Alone. Appl. Sci. 2021, 11, 3655. https://doi.org/10.3390/ app11083655

Academic Editor: Richard Kouzes

Received: 14 February 2021

Accepted: 17 April 2021

Published: 19 April 2021

Publisher's Note: MDPI stays neutral with regard to jurisdictional claims in published maps and institutional affiliations.

Copyright: (c) 2021 by the authors. Licensee MDPI, Basel, Switzerland. This article is an open access article distributed under the terms and conditions of the Creative Commons Attribution (CC BY) license (https:// creativecommons.org/licenses/by/ $4.0 /)$.

\begin{abstract}
Microcracks of depth less than $200 \mu \mathrm{m}$ in mechanical components are difficult to detect because conventional methods such as X-ray or eddy current measurements are less sensitive to such depths. Nonetheless, an efficient microcrack detection method is required urgently in the mechanical industry because microcracks are produced frequently during cold-forming. The frequency response function (FRF) is known to be highly sensitive even to microcracks, and it can be obtained using both the input data of an impact hammer and the response data of an accelerometer. Under the assumption of an impulse force with a similar spectral impulse pattern, spectral response data alone could be used as a crack indicator because the dynamic characteristics of a microcrack may be dependent solely on these measured data. This study investigates the feasibility of microcrack detection using the response data alone through impact tests with a simple rectangular specimen. A simple rectangular specimen with a $200 \mu \mathrm{m}$ microcrack at one face was prepared. The experimental modal analysis was conducted for the normal (uncracked) specimen and found-first bending mode about $1090 \mathrm{~Hz}$ at the X-Y plane (in-plane). Response accelerations were obtained in both at in-plane locations as well as X-Z plane (out-of-plane), and the crack was detected using the coherence function between a normal and a cracked specimen. A comparison of the crack inspection results obtained using the response data and the FRF data indicated the validity of the proposed method.
\end{abstract}

Keywords: microcrack; spectral response; impact input; nondestructive testing method; simple linear specimen

\section{Introduction}

Crack-free manufacturing is very difficult to achieve in mechanical industries. In fact, cracks occur inevitably on the surface of processed materials or products during plastic deformation. In particular, several microcracks can be observed during cold-forming because the deformation resistance of raw materials may be considerably higher than that during hot-forming. Inspectors performing quality inspections of the surface of a coldformed material subjected to plastic deformation must determine the depth of microcracks on the product. The identified microcrack depth and its reliability often depend strongly on the resolution of the applied nondestructive testing method.

Many nondestructive testing methods are available for crack detection, including acoustic emission sensor [1,2], fiber optic sensor [3,4], and Lamb wave excitation [5,6]. However, only a few methods are available for inspecting microcracks with depths of 100-200 $\mu \mathrm{m}$, and most of these require expensive inspection equipment. All detections or measurements were based on a small variation of the target system during the creation of a micro-depth crack [7-10]. Surface inspections using an eddy current sensor are currently applied widely in mechanical industries because they offer low costs and short inspection times. However, the minimum microcrack depth that can be detected exceeds $200 \mu \mathrm{m}$; microcracks shorter than $200 \mu \mathrm{m}$ cannot be detected. Based on a theoretical model for a basic structure such as beam, one study investigated the changes in dynamic characteristics depending on whether or not a microcrack is produced [10], and another investigated 
the frequency response characteristics by analyzing the sideband frequency near the covibration point in a cracked structure when applying a Lamb wave signal [6]. The high sensitivity of a frequency response function (FRF) to crack initiation can be used to inspect microcracks in a mechanical system [8]. The FRF has been used frequently to identify the dynamic behavior of a linear system and to extract the modal parameters, eigenvalue, and mode shape in the frequency domain [11,12]. FRFs can be measured by simply using an impact hammer or a modal exciter with low experimental cost compared to those of other nondestructive microcrack detection methods. A previous study detected microcracks experimentally by using the coherence function from measured FRFs in a mechanical component [13]. However, it could not be applied to practical problems because the signal processing to calculate the FRF between the input force data and the response data for the target mechanical components had to be conducted before judging the microcrack. In the present study, the feasibility of detecting microcracks from the response data alone was determined using a simple mechanical specimen subjected to a controlled input force produced using an impact hammer. The input force was controlled effectively as in Charpy impact tests [14,15], and both the spectral responses and the FRFs were calculated experimentally for two simple specimens with and without $200 \mu \mathrm{m}$ microcracks. By using the coherence function, the dynamic variation near the resonance frequency of a simple specimen could be detected for different response data locations. Microcracks could be detected successfully near the resonance frequency zone using both the spectral responses and the FRF; therefore, the microcrack depth could be predicted if the impact force could be controlled. Because crack detection using spectral response data alone is simpler than that using FRFs, the newly proposed method may be more effective for a practical inspection solution.

\section{Theoretical Approach}

This study aims to improve the existing FRF-based method for microcrack inspection. The FRF $(H(\omega))$ is given by Equation (1), where the impact from an impact hammer $(F(\omega))$ and the response $(R(\omega))$ are measured using acceleration sensors. Under the assumption of a system with linear characteristics, for normal products, the FRF given by Equation (1) can be calculated as shown in Figure 1.

$$
H(\omega)=\frac{R(\omega)}{F(\omega)}
$$

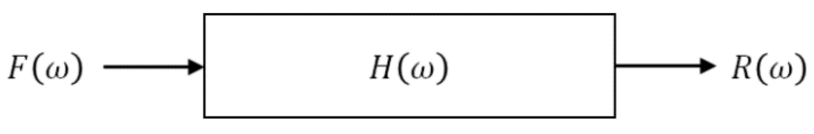

Figure 1. Relationship between input impulse and output response in normal system.

However, if a crack exists, the dynamic characteristics of the system as well as its FRF $(\widetilde{H}(\omega))$, input $(\widetilde{F}(\omega))$, and output $(\widetilde{R}(\omega))$ change, as shown in Figure 2.

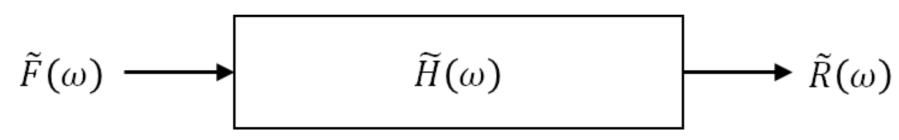

Figure 2. Relationship between input impulse and output response in abnormal system.

If the input signal applied by the impact hammer is almost identical to the Charpy impact test results shown in Figure 1, that is, $\widetilde{F}(\omega) \approx F(\omega)$, the FRF shown in Figure 2 can be expressed as

$$
\widetilde{H}(\omega)=\frac{\widetilde{R}(\omega)}{F(\omega)}
$$


Because a coherence function is used to evaluate the similarity of two FRFs, the corresponding indicator $(I(\omega))$ is formulated in Equation (3). Here, $G_{i, j}$ denotes the coherence function between $i$ and $j$ function in a frequency domain.

$$
I(\omega)=\frac{\left|G_{H(\omega) \widetilde{H}(\omega)}\right|^{2}}{G_{H(\omega) H(\omega)} G_{\widetilde{H}(\omega) \widetilde{H}(\omega)}}
$$

Upon substituting Equations (1) and (2) into Equation (3), the indicator (3) can be given as

$$
I(\omega)=\frac{\left|G_{[R(\omega) / F(\omega)][\tilde{R}(\omega) / F(\omega)]}\right|^{2}}{G_{[R(\omega) / F(\omega)][R(\omega) / F(\omega)]} G_{[\widetilde{R}(\omega) / F(\omega)][\tilde{R}(\omega) / F(\omega)]}} \approx \frac{\left|G_{R(\omega) \widetilde{R}(\omega)}\right|}{G_{R(\omega) R(\omega)} G_{\widetilde{R}(\omega) \widetilde{R}(\omega)}}
$$

Therefore, the previous indicator is a function of the response data if the input force signal can be controlled as soon as possible. This enables the inspection of microcracks in a mechanical system using the response data alone instead of the FRF.

\section{Crack Inspection with Simple Specimen}

To verify the theory, an impact experiment was conducted using a simple rectangular specimen, one end of which $(40 \mathrm{~mm})$ was clamped using a rigid body jig, as shown in Figure 3. Two simple specimens were prepared for the impulse test and the material of the responsible specimens was SS400 (POSCO, Pohang, South Korea); they differed in that one specimen had a microcrack along its middle at one face. The response data for these simple specimens were obtained using attached unidirectional accelerometers (\#1-\#6, Model: 3225F2, Dytran, Chatsworth, CA, USA), and that for the rigid body jig was obtained using another accelerometer (\#5), as shown in Figure 3. Three acceleration sensors (\#1, \#2, and \#5) were attached at the front planes $(X-Y)$, and the two sensors $(\# 3, \# 4)$ were attached at the rear planes $(X-Y)$ as shown in Figure 3. The other two acceleration sensors (\#5, \#6) were attached at orthogonal planes $(X-Z)$. Because the microcrack was located at node \#1, as shown in Figure 4a, the response at node \#1 was the nearest to the crack position (see Figure 5) and that at node \#2 was far from the cracked position on the same face of the specimen. The other specimen had no crack at node \#1, as shown in Figure 4b. Nodes \#3 and \#4 were at a similar distance from the cracked location in a manner corresponding to nodes \#1 and \#2, respectively, except that the face of the measured specimen was opposite to the cracked one. Because the specimen had a square cross section and the clamping area $(40 \mathrm{~mm} \times 19 \mathrm{~mm})$ was perpendicular to the two measured faces of the specimen, the boundary conditions for the two faces were assumed to be similar except for the existence of the crack.

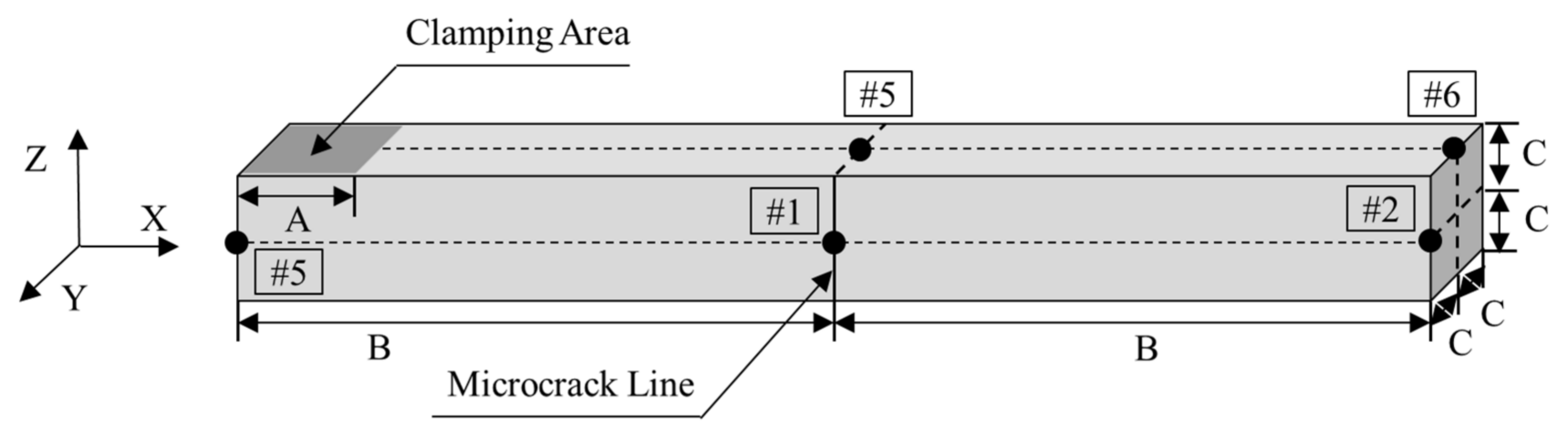

(a) Front view

Figure 3. Cont. 


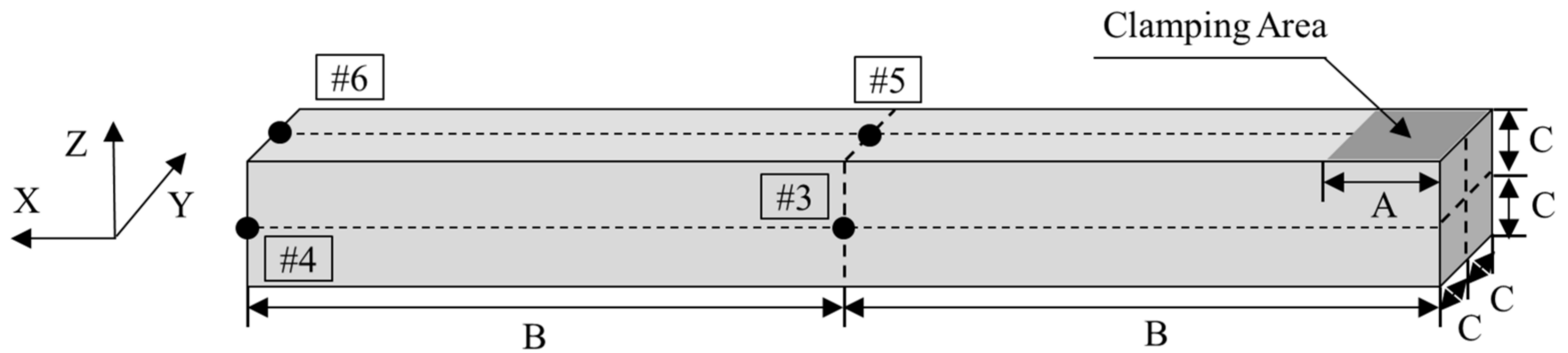

(b) Rear view

Figure 3. Configuration of simple specimen with one end clamped and sensor locations: A: $40 \mathrm{~mm}, \mathrm{~B}: 150 \mathrm{~mm}$, and C: $9.5 \mathrm{~mm}$.

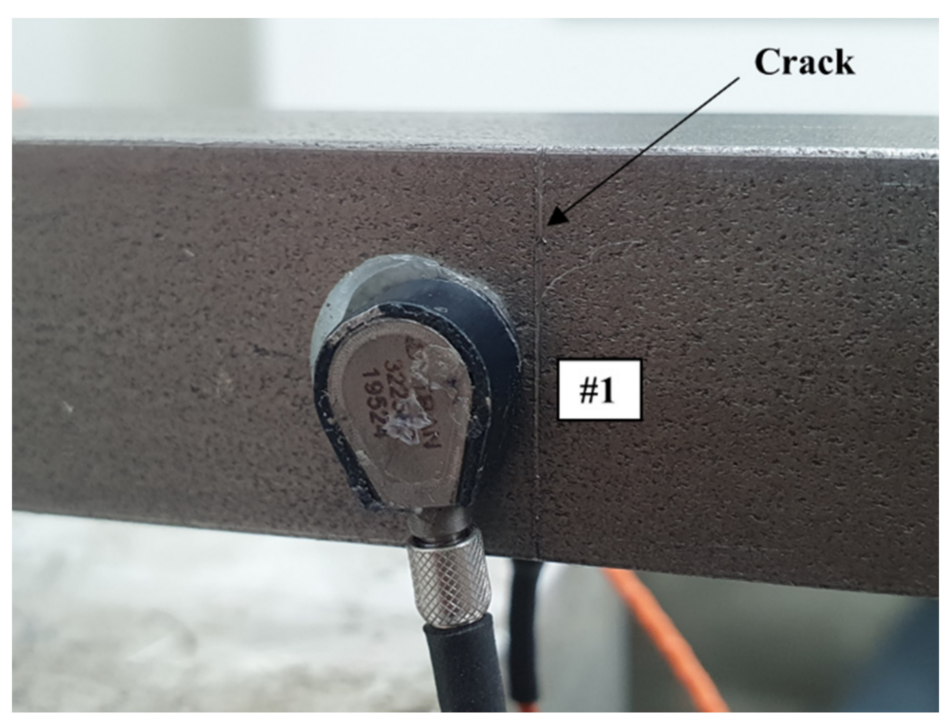

(a)

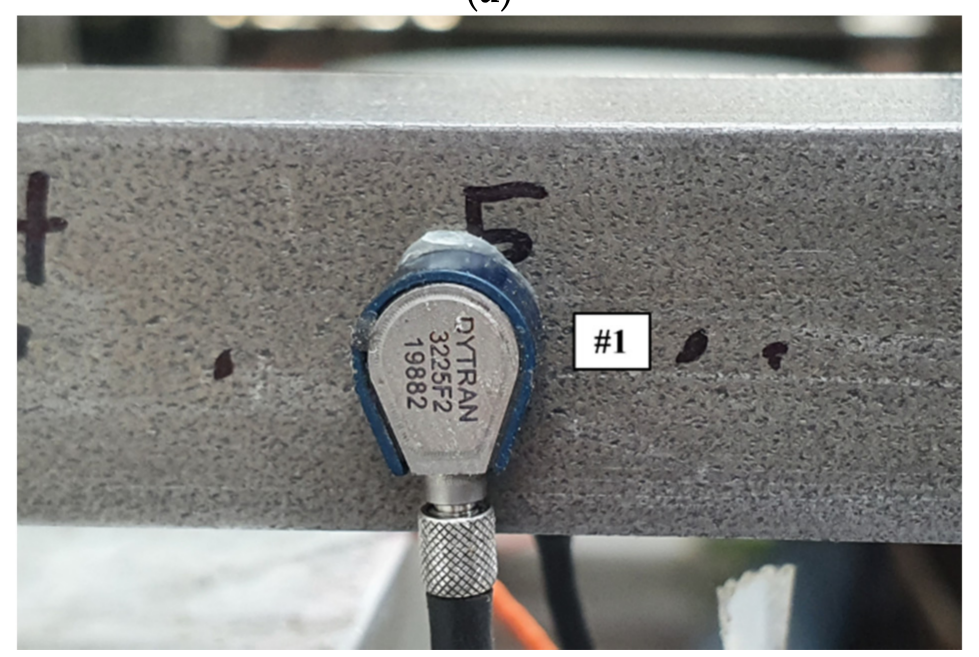

(b)

Figure 4. Attachment location of sensor \#1: (a) specimen with crack and (b) specimen without crack. 


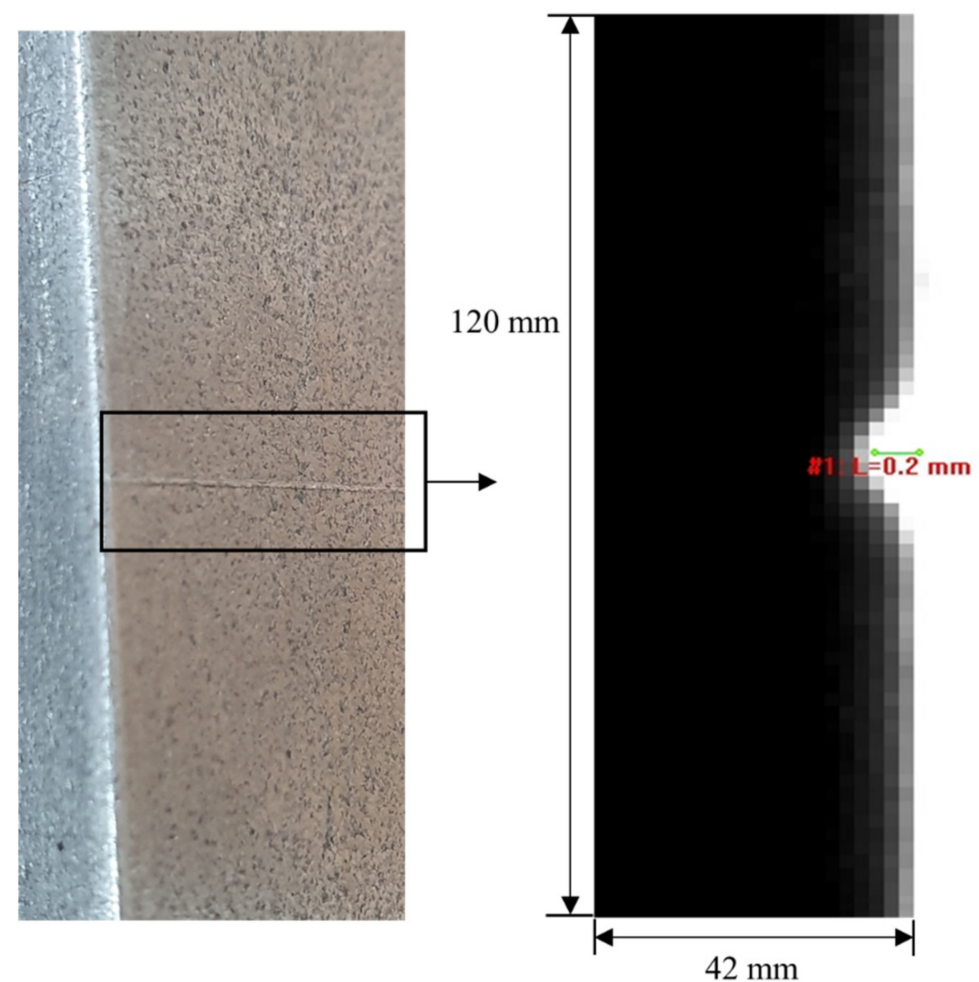

Figure 5. Measured maximum crack depth in simple specimen.

Before approaching the microcrack detection, the experimental modal analysis was preliminarily conducted for two rectangular simple specimens with and without microcrack as shown in Figure 4. The impact hammer (Model: 5800B3, Dytran, Chatsworth, CA, USA) was used to assign impact force at \#1, and response acceleration data were obtained at seven locations from \#1 to \#7, respectively. The acquisition of FRFs was done with TEST.LAB (Siemens, Munich, Germany), and the identification of modal parameters, both the resonance frequency and the modal damping coefficient, were conducted with PolyMax algorithm in TEST.LAB software. Maximum frequency was set to $3200 \mathrm{~Hz}$, and 1024 spectral lines were used during the modal parameter identification. In case of uncracked specimen case, the first bending mode was found at $1145 \mathrm{~Hz}$ (with $0.38 \%$ damping coefficient) and the $X-Y$ plane was in-plain mode, whereas the first mode of cracked specimen was $1090 \mathrm{~Hz}$ ( $0.51 \%$ damping coefficient, in-plain for $X-Z$ plane) and the second bending mode could be identified at $1150 \mathrm{~Hz}$ (1.15\% damping coefficient, in-plain for X-Y plain). The modal assurance criterion (MAC) value between two bending mode showed 0.57 owing to the orthogonality between X-Z plane and X-Y plane. The third peak of the cracked specimen was also found at $1185 \mathrm{~Hz}$ but that mode was not considered because MAC value between the second bending mode and the third one was 92.3 so that two peaks seemed to be very similar each other. The resonance frequency of the rectangular simple specimen was decreased from $1145 \mathrm{~Hz}$ to $1090 \mathrm{~Hz}$, and sideband frequencies were also initiated under the presence of microcrack at the simple specimen. The results of two rectangular simple specimen of the modal analysis are summarized in Table 1.

Table 1. Summary of experimental modal analysis for two specimens.

\begin{tabular}{cccc}
\hline Specimen & $\begin{array}{c}\text { Resonance } \\
\text { Frequency (Hz) }\end{array}$ & Modal Damping (\%) & $\begin{array}{c}\text { Mode Shape } \\
\text { (In-Plane) }\end{array}$ \\
\hline No crack & 1145 & 0.38 & Bending (X-Y plane) \\
\hline \multirow{2}{*}{ Crack } & 1090 & 0.51 & Bending (X-Y plane) \\
& 1150 & 1.15 & Bending (X-Z plane) \\
\hline
\end{tabular}


The first bending mode can be found at $1090 \mathrm{~Hz}$ (with $0.39 \%$ modal damping coefficient) and only effective on X-Y planes. In case of cracked specimen, another impact hammer test was also conducted by assigning the impact force at \#5 to figure out the behavior at $X-Z$ plane more visibly. However, the modal test result was similar to the impact hammer case at \#1. Accordingly, both X-Y planes and X-Z plane are denoted as the in-plane and the out-of-plane for the first bending mode. Second mode could not be found under the maximum frequency band, $3200 \mathrm{~Hz}$. That means the response at \#6, \#7 was small at the resonance frequency so that the microcrack detection at the two locations will be less reliable as compared to other measurement locations, \#1 \#4. The crack detection was mainly conducted for the four measured data, from \#1 to \#4, and the results from the out-of-plane locations, \#6 and \#7, are discussed later.

The microcrack depth was measured using X-ray equipment (Dual Tube 3D CT, TECHVALLEY, South Korea), and the maximum depth was $200 \mu \mathrm{m}$, as shown in Figure 5. Therefore, the crack depth in the specimen was acceptable for inspection.

Under these conditions, another test set-up with an impact hammer was designated to measure the response data by imposing an impact force at locations \#1-\#6 in both specimens. Figure 6 shows the measured impact forces in the specimen with a crack. To impose the same impact force on the target specimen, the impact hammer was moved with a circular trajectory by clamping one end of the impact hammer as in the Charpy impact test, as shown in Figure 7. The experimental results indicated that the impact hammer was setup suitably, and the similar impulse spectrum pattern obtained indicated that the approximation in Equation (2) was acceptable.

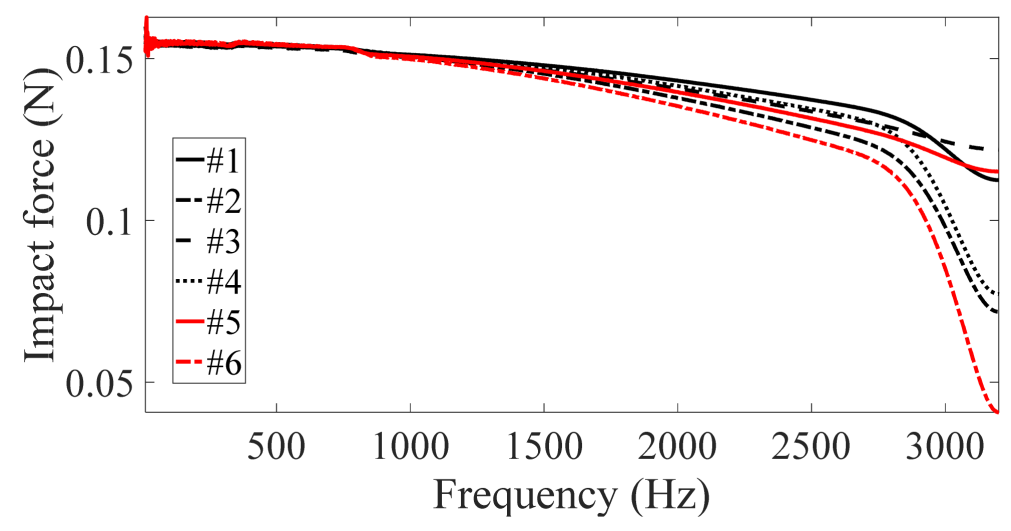

Figure 6. Impact force at input locations \#1-\#6.

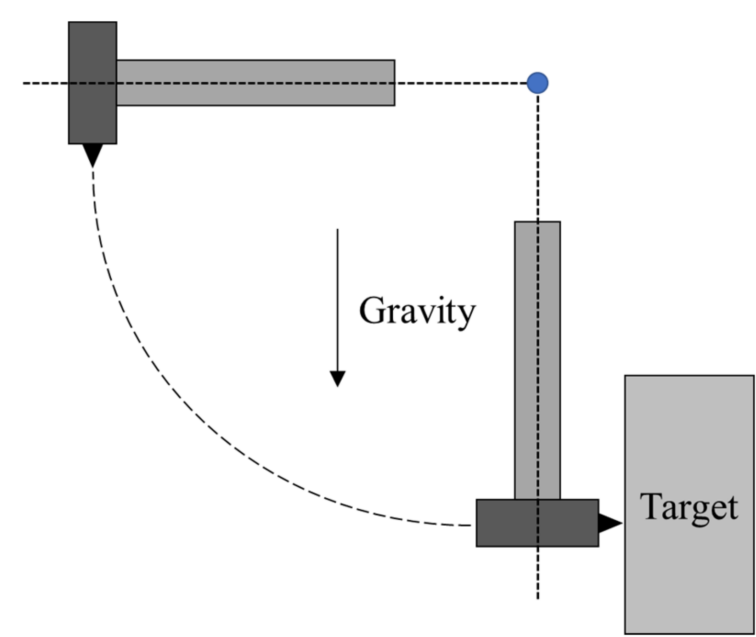

Figure 7. Setup of impact hammer (similar to that in Charpy impact test). 
When an impulse force was imposed using the impact hammer at node $\# i$, the response accelerations were measured at all sensor-attached locations in Figure 3. In practice, it was difficult to localize the microcrack from the target structure of inspection so that the microcrack inspection method would consider the distance between the impact position and the microcrack position, in the determination of microcrack existence. So, the response data were only considered for the same location of impact position, and the relationship between the crack indicator (see the Equations (3) and (4)) and the measurement position was analyzed in this study. In each case of impulse force input at node $\# i$, the response acceleration at the same node $\# i$ was selected and shown in Figure 8 for two rectangular simple specimens with and without microcrack. Sideband frequencies between 1000 and $1200 \mathrm{~Hz}$ that were derived from the crack position were seen at nodes \#1 and \#3 near the crack; these frequencies seemed very sensitive to the distance from the crack. In case of uncracked specimen, single frequency peak could be found at X-Y plane, \#1 \#4, and small peak were also shown in X-Z plane, \#5 and \#6, near $1145 \mathrm{~Hz}$ frequency. In case of cracked specimen, the frequency peak was observed near $1090 \mathrm{~Hz}$ at $X-Y$ plane, \#1 \#4, and small two sideband frequencies were found at \#1 and \#2 (front face of $X-Y$ plane). On the other hand, the sideband frequencies were highlighted at X-Z plane, \#5 and \#6, but the bending mode near $1090 \mathrm{~Hz}$ was relatively small. Those responses were well matched with the experimental modal test results in Table 1.

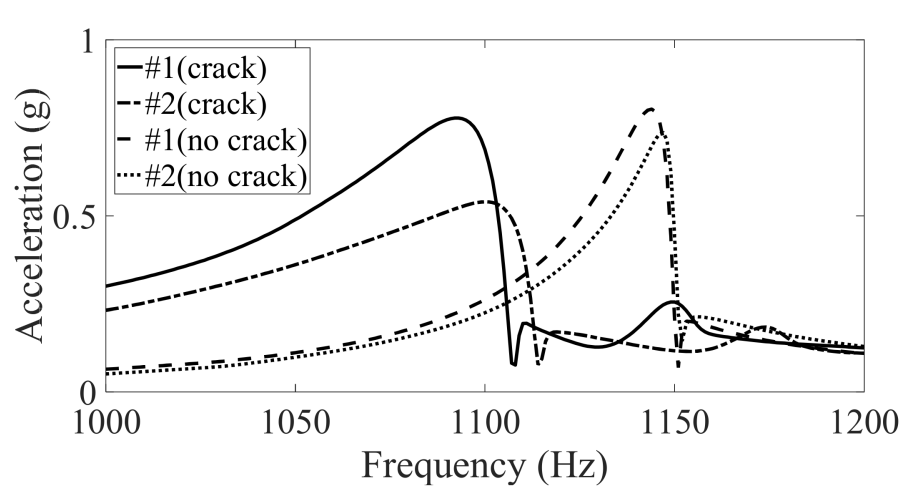

(a)

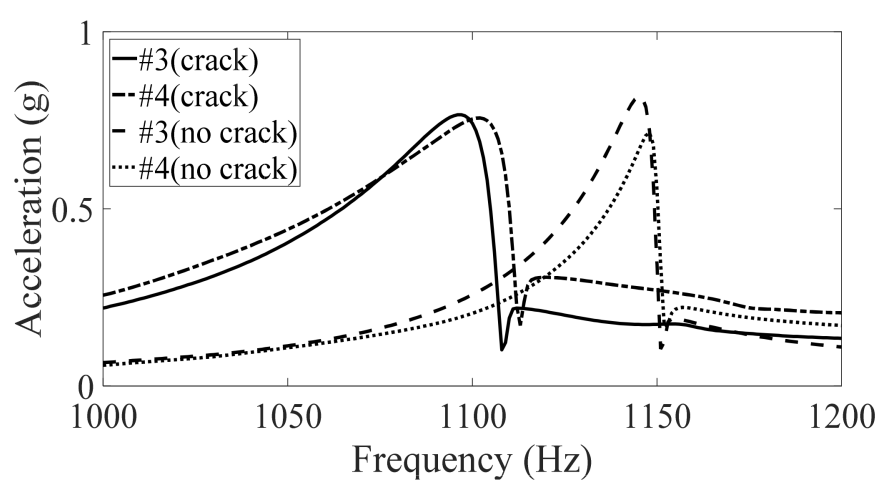

(b)

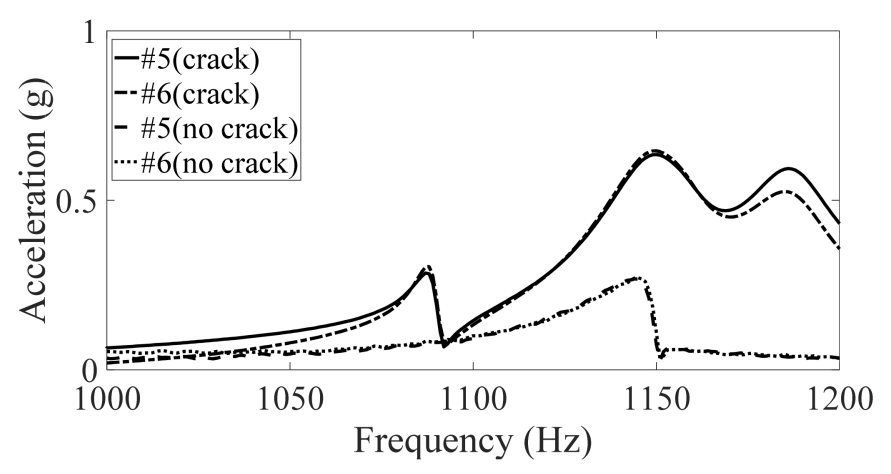

(c)

Figure 8. Acceleration response of two specimens: (a) X-Y plane (front), (b) X-Y plane (rear), and (c) X-Z plane.

The coherence functions were calculated using the FRFs in both specimens, as shown in Figures 9a, 10a and 11a, respectively. All six coherence functions were sensitive to two frequencies: resonance frequency at $\sim 1090 \mathrm{~Hz}$ and sideband frequency at $1150 \mathrm{~Hz}$. These results verified the previous study of microcrack detection. The crack indicator at the sideband frequency decreased rapidly regardless of the measurement location, and the coherence values near the resonance frequency varied according to the measurement location. The indicating frequency at the minimum coherence values was lower at \#1, 
\#2 (front face in X-Y plane) than \#3, \#4 (rear face in X-Y plane) near $1090 \mathrm{~Hz}$. In case of $X-Z$ plane, the sensitivity near the resonance frequency at $1090 \mathrm{~Hz}$ was not remarkable and additional sensitive frequency could be found at $1145 \mathrm{~Hz}$ because the $X-Z$ plane was out-of-plane of the bending mode shape at $1090 \mathrm{~Hz}$. Therefore, the suitable frequency for microcrack detection is the sideband frequency rather that the resonance frequency as in the FRF case.

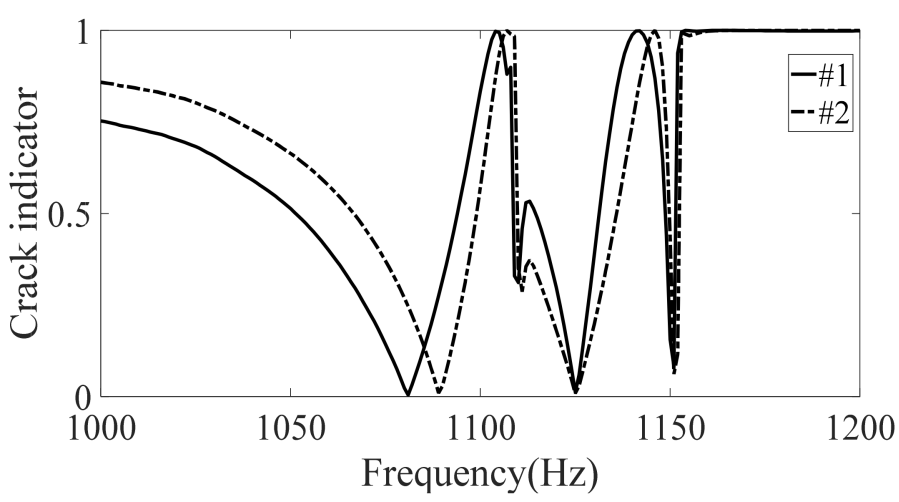

(a)

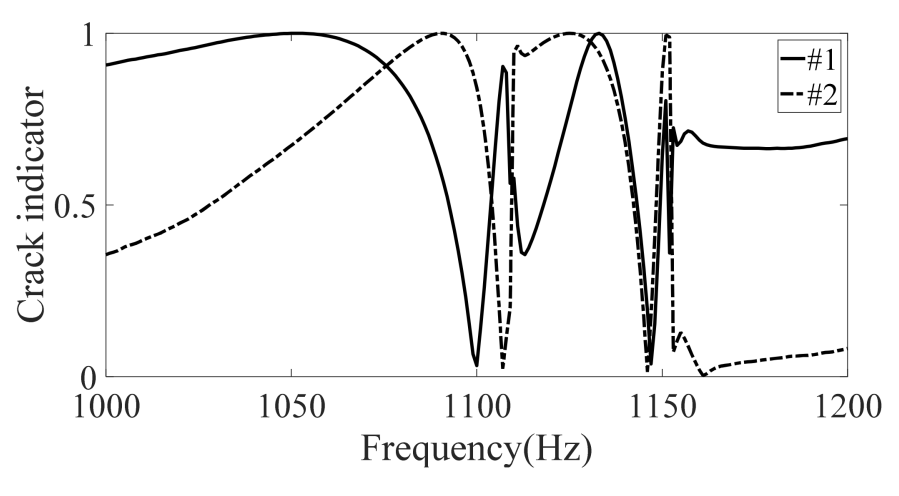

(b)

Figure 9. Crack indicator in $X-Y$ plane (front): (a) frequency response function and (b) acceleration only.

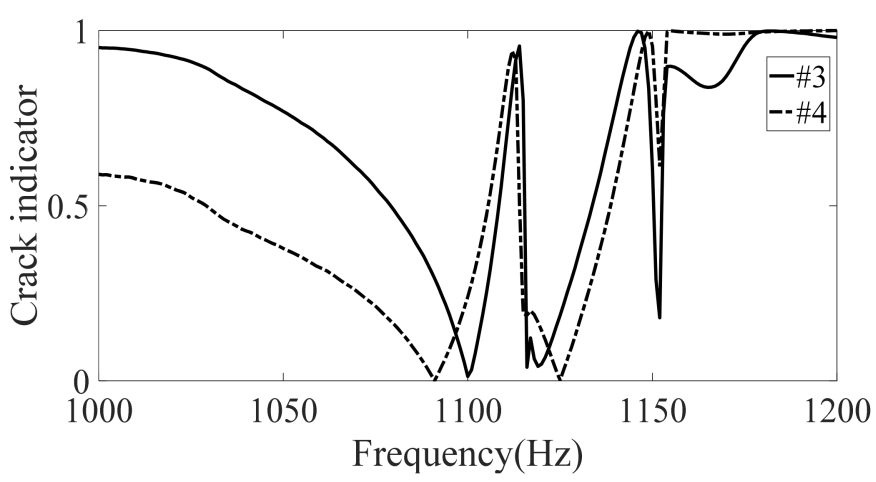

(a)

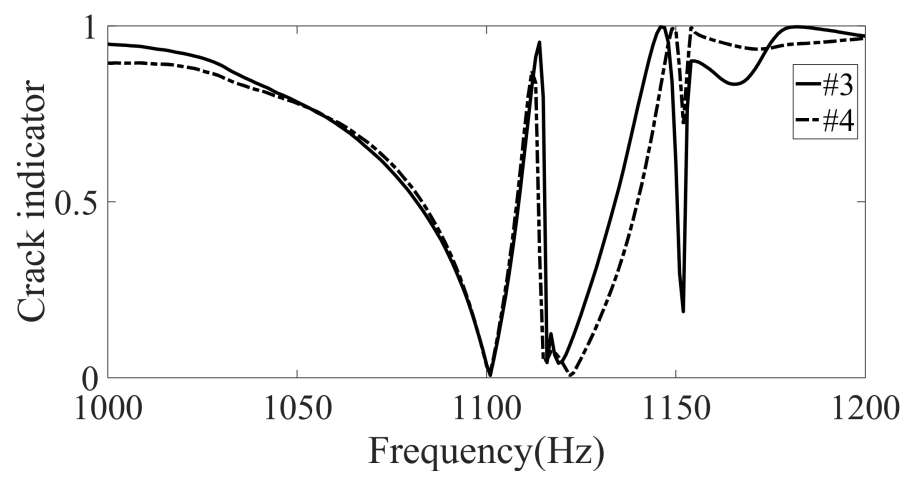

(b)

Figure 10. Crack indicator in $X-Y$ plane (rear): (a) frequency response function and (b) acceleration only.

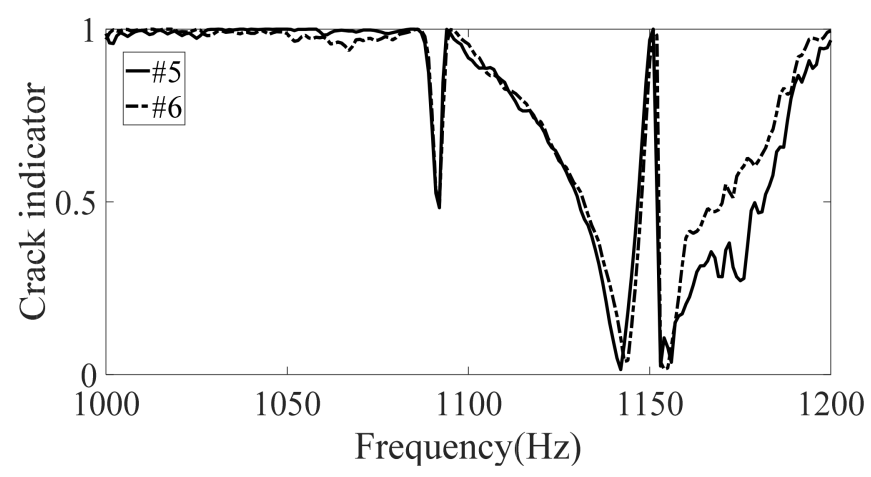

(a)

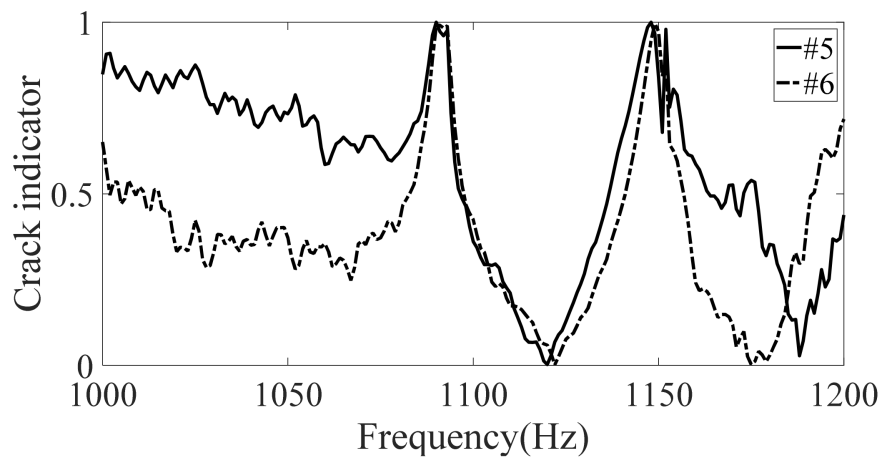

(b)

Figure 11. Crack indicator in X-Z plane: (a) frequency response function and (b) acceleration only.

The same coherence function was used with response data alone for crack detection, and the results for the cracked and the uncracked face (see Figure 3) are shown in 
Figures $9 \mathrm{~b}, 10 \mathrm{~b}$ and $11 \mathrm{~b}$, respectively. For the $X-Y$ plane (front), locations \#1 and \#2 were both very sensitive to the sideband frequency, whereas the sensitivity to the resonance frequency differed with the measurement position. For the X-Y plane (rear), locations \#3 and \#4 both showed similar sensitivity to the resonance frequency; by contrast, location \#3 (near the crack) showed high sensitivity to the sideband frequency whereas location \#4 did not. The coherence function in X-Z plane was not similar to X-Y plane; the most sensitive frequency was at $\sim 1121 \mathrm{~Hz}$ and the least sensitive frequencies were $1090 \mathrm{~Hz}$ and $1145 \mathrm{~Hz}$. The difference results in X-Z plane were caused by the orthogonality between two resonance frequencies in cracked specimen. So, the sensitivity in microcrack detection was dependent on the measurement position, and the mode shape of target structure will be critical factor to select the suitable position of sensor location.

The crack indicator obtained using the FRF was relatively consistent for all measurement locations and seemed less dependent on the distance from the crack position if the measurement location was in-plane with the critical mode shape of cracked specimen. The only limitation was the sideband frequency at \#4. An inspection methodology that is independent of the crack position will be beneficial because it is difficult to determine the exact location of a crack in a target structure in advance. In case of out-of-plane measurement, the sensitivity of crack detection was partially applicable at sideband frequency and not valid for the resonance frequency. As shown in Figures 9a, 10a and 11a, this advantage holds even for crack inspection using the response data alone, although the crack indicator at each measurement location showed a different coherence value in the resonance frequency zone when the measurement position belonged to in-plane mode with the critical mode shape. The sideband frequency decreased rapidly except at measurement location \#4, and these results were similar to the FRF cases. These results indicate the feasibility of the crack indicator obtained using the response data alone for the sideband frequency with minor dependency on the measurement location, and the resonance frequency seems usable if the measurement allows location dependency.

The difference in the crack indicator obtained using these two different methods may arise from the difference of the phase information in the frequency domain, because the proposed method assumed similar input forces even though it is impossible to control the phase of the impulse force in practice. Nonetheless, the crack indicator obtained using the response data alone is advantageous compared with the previous FRF-based method owing to its simple calculation process and the lack of the need for information of the input impulse force. Therefore, the crack indicator obtained using the response data alone should be used preferentially if the crack sensitivity can vary by a small margin with the measurement location.

The limitation of this study was the dynamic dependency on the rectangular simple specimen. The orthogonality between two resonance frequencies in the cracked specimen was not explained, and both the in-plane and out-of-plane may not be valid for other shape of specimen, if the cross-section was round. In addition, the localization of microcrack was not possible from the proposed crack indicator. Both of issues will be future work from current studies.

\section{Conclusions}

The feasibility of using spectral response data as a crack indicator was investigated and verified through experiments with simple specimens. An impact force was imposed using an impact hammer, and the responses at six different locations on the specimen were measured. The theoretical crack indicator was derived under the assumption that the input impact force is similar in all experimental cases. The sensitivity of the FRF was verified in accordance with a previous study and was found to be less dependent on the distance of the measurement location from the microcrack if the measurement location was in-plane with the responsible mode shape. The resonance frequency and the sideband frequency can be used as crack indicators; between the two, the sideband frequency was considered more suitable for crack detection because the coherence value from the original 
frequency varied with the measurement location. The crack indicator may be partially applicable at sideband frequency region if the measurement was done at out-of-plane with the critical mode shape. When using response data alone, the feasibility of microcrack detection can be proved using the crack indicator at these two frequencies as in the FRF case. However, the crack indicator obtained using the coherence function revealed that the dependency of these frequencies on the measurement location was higher than in the FRF case. For the in-plane (front) measurement locations, \#1 and \#2, the crack indicator at the sideband frequency was very sensitive whereas that at the resonance frequency varied at location \#2. For other in-plane (rear) measurement locations, \#3 and \#4, the sensitivity at the sideband frequency decreased at location \#4 (far from crack) but not at location \#3; however, the sensitivity at the resonance frequency for these two measurement locations was consistently high. However, in case of out-of-plane measurement case, \#5 and \#6, the two sensitive frequencies were not valid for the crack indicator. So, the microcrack detection with response data only should consider the mode shape of critical resonance frequency by allocating all measurement location at in-plane. Under these requirements, the feasibility of microcrack detection is possible with response data only.

Author Contributions: Conceptualization, C.-J.K.; methodology, C.-J.K.; validation, C.-J.K. and G.-S.L.; formal analysis, G.-S.L.; investigation, C.-J.K.; resources, C.-J.K.; data curation, C.-J.K. and G.-S.L.; writing-original draft preparation, C.-J.K.; writing—review and editing, C.-J.K. and G.-S.L.; project administration, C.-J.K. All authors have read and agreed to the published version of the manuscript.

Funding: This research received no external funding.

Institutional Review Board Statement: Not applicable.

Informed Consent Statement: Not applicable.

Data Availability Statement: Not applicable.

Acknowledgments: This work was supported by a Research Grant from the Ministry of Science and ICT/South Korea (\#1711124126, 2020).

Conflicts of Interest: The authors declare no conflict of interest.

\section{References}

1. Behrens, B.A.; Santangelo, A.; Buse, C. Acoustic emission technique for online monitoring during cold forging of steel components: A promising approach for online crack detection in metal forming processes. Prod. Eng. 2013, 7, 423-432. [CrossRef]

2. El-Galy, I.; Behrens, B.A. Online monitoring of hot die forging processes using acoustic emission (Part I). J. Acoust. Emiss. 2008, 26, 208-219.

3. Sante, R.D. Fiber optic sensors for structural health monitoring of aircraft composite structures: Recent advances and applications. Sensors 2015, 15, 18666-18713. [CrossRef] [PubMed]

4. He, J.; Yang, J.; Wang, Y.; Waisman, H.; Zhang, W. Probabilistic model updating for sizing of hole-edge crack using fiber Bragg grating sensos and the high-order extended finite element method. Sensors 2016, 16, 1956. [CrossRef] [PubMed]

5. He, J.; Ran, Y.; Liu, B.; Yang, J.; Guan, X. A fatigue crack size evaluation method based on lamb wave simulation and limited experimental data. Sensors 2017, 17, 2097. [CrossRef] [PubMed]

6. Jingpin, J.; Xiangji, M.; Cunfu, H.; Bin, W. Nonlinear lamb wave-mixing technique for micro-crack detection in plates. Ndte Int. 2017, 85, 63-71. [CrossRef]

7. Gupta, A.; Jain, N.K.; Salhotra, R.; Rawani, A.M.; Joshi, P.V. Effect of fibre orientation on non-linear vibration of partially cracked thin rectangular orthotropic micro plate: An analytic approach. Int. J. Mech. Sci. 2016, 105, 378-397. [CrossRef]

8. Ravi, D.; Liew, K.M. A study of the effect of microcrack on the vibration mode shape. Eng. Struct. 2000, 22, 1097-1102. [CrossRef]

9. Shaat, M.; Khorshidi, M.A.; Abdessattar, A.; Shariati, M. Modeling and vibration characteristics of cracked nano-beams made of nanocrystalline materials. Int. J. Mech. Sci. 2016, 115-116, 574-585. [CrossRef]

10. Gupta, A.; Jain, N.K.; Salhotra, R.; Joshi, P.V. Effect of crack location on vibration analysis of partially cracked isotropic and FGM micro-plate with non-uniform thickness: An analytical approach. Int. J. Mech. Sci. 2018, 145, 410-429. [CrossRef]

11. Ewins, D.J. Modal Testing, 2nd ed.; Research Studies Press Ltd.: Hertfordshire, UK, 2000.

12. Inman, D.J. Engineering Vibration, 4th ed.; Pearson: Singapore, 2013. 
13. Kim, C.J.; Kang, I.P.; Sohn, J.H.; Kim, B.T. Micro crack detection of mechanical part using coherence function near resonance frequency. In Proceedings of the 8th International Conference on Engineering Failure Analysis, Budapest, Hungary, 8-11 July 2018; p. 39.

14. Toshiro, K.; Isamu, Y.; Mitsuo, N. Evaluation of dynamic fracture toughness parameters by instrumented Charpy impact test. Eng. Fract. Mech. 1986, 24, 773-782. [CrossRef]

15. Rossoll, A.; Berdin, C.; Prioul, C. Determination of fracture toughness of a low alloy steel by the instrumented Charpy impact test. Int. J. Fract. 2002, 115, 205-226. [CrossRef] 